UAM Vol. 40/1 Poznań 2013

\title{
ESTUDOS LINGUÍSTICOS
}

\author{
CELDA MORGADO CHOUPINA \\ Universidade Politécnico do Porto \\ celda@ese.ipp.pt
}

\section{CONTRIBUTOS PARA UMA ANÁLISE SINTÁTICA DOS OBJETOS COGNATOS EM PE}

\begin{abstract}
Celda Morgado Choupina, Contributos para uma análise sintática dos objetos cognatos em $P E$ [Towards a syntactic analysis of European Portuguese cognate objects], Studia Romanica Posnaniensia, Adam Mickiewicz University Press, Poznań, vol. XL/1: 2013, pp. 59-79. ISBN 978-83-232-2542-3. ISSN 0137-2475. eISSN 2084-4158.
\end{abstract}

The present paper aims at discussing selected syntactic aspects of cognate objects in European Portuguese, along the lines of Distributed Morphology (Haugen, 2009). Cognate objects may be readily discovered in numerous human languages, including European Portuguese (Chovia uma chuva miudinha). It is assumed in papers devoted to their English counterparts that they belong to various subclasses. Indeed, some of them are genuine cognates (to sleep a sleep ...) or hyponyms (to dance a jig; Hale \& Keyser, 2002). It turns out that in European Portuguese, they can be split into four different categories: (i) genuine cognate objects (chorar um choro...), (ii) similar cognate objects (dançar uma dança) (iii) objects hyponyms (dançar um tango) and (iv) prepositional cognate objects (morrer de uma morte ...). There are, then, significant differences between various classes of cognate objects: whereas the genuine ones call imperatively for a restrictive modifier and a definite article, the remaining ones admit it only optionally. It might be concluded, then, that a lexicalist theory set up along the lines of Hale and Keyser is unable to deal successfully with distributional facts proper to various classes of cognate constructions in European Portuguese. That is why the present study is conducted more in accordance with syntactic principles of Distributed Morphology, with a strong impact of hypotheses put forward by Haugen (2009).

Keywords: syntax, cognate objects, Distributed Morphology

\section{INTRODUÇÃO}

O presente artigo tem como objetivo analisar alguns aspetos sintáticos dos objetos cognatos em Português Europeu (PE), no quadro da Morfologia Distribuída (MD).

Entenderemos a cognação como uma relação não só etimológica (cognato como termo aplicado tradicionalmente a palavras com a mesma origem), mas também como uma relação semanticamente pleonástica - como em subir para cima, entrar para 
dentro (na esteira de Gallego, 2012). O alargamento do termo cognato a esta última aceção permite-nos considerar nomes como sono/sueño/sommeil cognatos de dormir (por uma relação semanticamente pleonástica).

Atendendo a esta definição e partindo dos contributos da MD, propomo-nos abordar algumas das construções com objetos cognatos (OC) em PE. Distinguiremos, assim, (i) os objetos cognatos morfologicamente relacionados com o verbo (por relação etimológica ou não), chorar um choro.../sonhar um sonho, denominados objetos cognatos verdadeiros (OC verdadeiros); os objetos não morfologicamente relacionados mas que têm uma dependência semântica em relação ao verbo e não podem ser substituídos por um cognato morfológico, dormir um sono... vs *dormir uma dormida, (OC verdadeiros); (ii) os objetos cognatos morfologicamente relacionados com o verbo, sem restrições de indefinitude nem modificação, dançar uma dança ..., ou objetos cognatos aparentados (OC aparentados); (iii) os objetos hipónimos que exprimem um subtipo da entidade denotada pelo nome cognato, dançar um tango / uma valsa / um vira ...( (OH); e ainda (iv) os SP com nome cognato, como em caminhar por um caminho dificil, ou objetos cognatos preposicionais (OCP).

$\mathrm{Na}$ primeira parte do artigo faremos uma abordagem descritiva do fenómeno em PE, ainda que sejam aduzidos, contrastivamente, alguns dados de outras línguas românicas e do Inglês. É nosso intuito sistematizar, a partir dos critérios sintático-semânticos de definitude e modificação, algumas restrições distribucionais dos OC verdadeiros (chorar um choro...), a fim de estabelecer uma fronteira entre este tipo de construção e outros tipos de construções com OC (dançar uma dança/um tango).

Como veremos adiante, a teoria de Hale \& Keyser (1993, 2002), construída num quadro lexicalista forte ${ }^{1}$ (l-syntax), embora proposta para dar conta destes fenómenos em Inglês, não permite analisar adequadamente vários fenómenos relacionados com todos os tipos de OC existentes nas línguas românicas, tornando-se necessário explorar outras abordagens, como veremos no ponto 2. deste texto. Neste sentido, consideramos que as teorias da MD nos trazem um contributo interessante e capaz de resolver, parcialmente, algumas questões relacionadas com as construções com $\mathrm{OC}$ e as quatro classes que nelas se integram, no âmbito do PE. Apresentaremos, na secção 3., o contributo de Haugen (2009), no quadro da MD, e, finalmente, na última parte (secção 4), tentaremos a nossa proposta para algumas das construções em estudo.

${ }^{1}$ O Lexicalismo é centrado na hipótese da existência de um repositório - o léxico - que contém palavras já formadas e que são inseridas na sintaxe. Duas correntes de análise se destacaram dentro desta teoria: (i) o Lexicalismo Forte: palavras derivadas e palavras flexionadas são formadas no léxico e (ii) O Lexicalismo Fraco: palavras derivadas são formadas no léxico e palavras flexionadas são formadas na própria sintaxe. Nas duas versões da teoria lexicalista, são postulados dois espaços generativos na arquitetura da gramática: o léxico e a sintaxe. 


\section{DESCRIÇÃO DO FENÓMENO DOS OC EM PE}

\subsection{PRIMEIRA ABORDAGEM}

Em PE e em várias línguas do mundo têm sido notadas construções com objetos $\operatorname{cognatos}^{2}$ como os exemplos (1) a (4) ilustram:

(1) [Português Europeu]

a) Chovia uma chuva miudinha.

b) Os guerreiros dançam uma dança frenética à volta de um totem.

c) Dormimos um sono reparador. (Duarte e Brito, 2003: 185)

(2) [Espanhol]

a) Reir la risa de un niño. (Mendikoetxea, 1999: 1578)

b) Juan cantó una canción. (Gallego, 2008: 6)

c) Dormir un sueño tranquilo. (Mendikoetxea, 1999: 1578)

(3) [Francês]

a) Il a dansé une (grande) danse. (Pereltsvaig, 2001)

b) Elle a chanté une (belle) chanson. (Pereltsvaig, 2001)

c) Pleurer toutes les larmes de son corps. (Grevisse \& Goose, 1993: 393)

(4) [Inglês]

a) He laughed his last laugh. (Hale \& Keyser, 2002: 71)

b) Louise sang a (beautiful) song. (Pereltsvaig, 2001)

c) She slept the sleep of the just. (Hale \& Keyser, 2002: 71)

Estes dados apresentam o que normalmente é denominado OC (Hale \& Keyser, 1993, 2002) ou argumentos sombra (Pustejovsky, 1998), sendo que alguns dos nomes em itálico nos exemplos são da mesma família morfológica dos verbos que os precedem (com relação etimológica ou não), como em chover-chuva (1a), dançar-dança (1b), reir-risa (2a), cantar-canción (2b), danser-danse (3a); chanter-chanson (3b); to laugh-laugh (4a), to sing - song (4b).

No entanto, a relação morfológica entre verbo e nome não é a mesma em todas as línguas e para todos os pares V-N. Com efeito, se em Inglês to sleep-sleep (4c) apresentam o mesmo radical (homonímia perfeita), em português dormir-sono (1c) e em espanhol dormir-sueño (2c) apenas se relacionam semanticamente. Em parte por esta razão, estes objetos, que acompanham verbos tradicionalmente considerados de

${ }^{2}$ Estas construções têm sido notadas e analisadas em várias línguas: Jones (1988), Massam (1990), Hale \& Keyser (1993, 2002), Matsumoto (1996), Horita (1996), Kitahara (2006, 2007), Mirto (2007), Höche (2009), Haugen (2009), Sailer (2010), entre outros, para o Inglês; Gallego (2008, 2012) para o Inglês, o Basco e o Espanhol; Pereltsvaig (1999a e b) para o Russo; Mittwoch (1998) e Pereltsvaig (2001) para o Hebreu; Pham (1998) para o Vietnamita; Hong (1999) para o Chinês; Real-Puigdollers (2008) para o Inglês e as Línguas Românicas; Leung (2006, 2007) e Silva (2010) para o Português do Brasil; Choupina (2011, 2012a e b) para o Português Europeu, entre outros. 
0 argumentos (chover), de 1 argumento (como os inergativos reir, to sleep) ou de alternância 1/2 argumentos (os verbos de alternância intransitiva/transitiva como cantar, dançar), são claramente pleonásticos do ponto de vista semântico e, como veremos adiante, altamente restringidos do ponto de vista sintático.

Devemos, desde já, notar que as condições distribucionais podem ser também diferentes de língua para língua: se em PE é obrigatória a modificação e a definitude para alguns nomes (chover-chuva (1a), dormir-sono (1c), noutras línguas, como em Francês, observa-se a opcionalidade destas propriedades (danser-danse (3a); chanterchanson (3b)).

Estas diferenças e outras observáveis nos exemplos (1) a (4) mereceriam ser exploradas. No entanto, neste trabalho, debruçar-nos-emos essencialmente sobre os dados do PE.

\subsection{RESTRIÇÕES DISTRIBUCIONAIS DOS OC EM PE: OS OC VERDADEIROS}

Nos exemplos do PE (1), os objetos cognatos são constituídos por um determinante indefinido, um nome e um adjetivo que o restringe, o que revela que a indefinitude e a modificação são uma condição sine qua non para a boa formação destas construções nesta língua.

Com efeito, os testes de definitude e de modificação apresentados a seguir mostram que em PE os objetos cognatos devem ser indefinidos e modificados para serem aceitáveis, o que permitirá estabelecer uma primeira fronteira no seio dos OC, delimitando os OC verdadeiros (5) e outras construções OC (6).

(5) a) *Chovia a chuva miudinha.

b) *Chovia uma chuva.

(6) a) ?Os guerreiros dançam a dança frenética à volta de um totem.

b) Os guerreiros dançam uma dança.

Também relativamente a dormir e no que diz respeito a (1c) se verificam as mesmas restrições que em (5) (cf. (7)), embora estejamos perante uma construção diferente das anteriores, dada a relação semântica, não morfológica, que o nome (núcleo do $\mathrm{SN}$ objeto) estabelece com o verbo.

(7) a) *Dormimos o sono reparador.

b) *Dormimos um sono.

Este tipo de construção (dormir-sono) surge em línguas que não permitem uma coocorrência com um nome do tipo cognato morfológico, (8).

(8) *Dormimos uma dormida reparadora ${ }^{3}$.

${ }^{3}$ Este teste levanta diversas questões que os limites do texto não permitem analisar em detalhe: a) por um lado, é crucial saber da existência ou não do nome cognato no próprio léxico da língua (em Francês, tal como em Português e Espanhol, existe pleurer $_{\mathrm{v}}-$ pleur $_{\mathrm{N}}$, mas dormir $_{\mathrm{v}}$ não tem qualquer 
No entanto, as construções dormir-sono serão também consideradas OC verdadeiros, integradas como um subtipo.

Embora a construção com um modificador restritivo pareça ser uma exigência dos objetos verdadeiros nas línguas apresentadas em (1) - (4), o critério da definitude não tem sido considerado, na literatura, absolutamente uniforme em todas as Línguas Românicas ( $c f$. Real-Puigdollers, 2008: 170). Esta autora considera que o Espanhol, o Italiano e o Francês não apresentam obrigatoriedade de indefinitude no objeto cognato e a partir daí alarga a ideia às Línguas Românicas. No entanto, afastar-nos-emos da conceção de Real-Puigdollers (2008: 170), por não aceitarmos que exemplos estritamente literários e/ou expressões idiomáticas (cf. (9) e (10)) possam ser aduzidos para fundamentar a heterogeneidade dentro das Línguas Românicas e destas com o Inglês. Vejam-se, entre outros, os exemplos (2a) e (4c), aqui repetidos.

(9) Reir la risa de un niño.

(10) She slept the sleep of the just.

Quer dizer, (9) e (10), em Espanhol e em Inglês, respetivamente, por conterem expressões idiomáticas, lexicalizadas, não permitem concluir que estas línguas, portanto, não exijam a indefinitude do objeto cognato.

Voltando aos OC verdadeiros, em PE, estes objetos surgem na posição típica de $\mathrm{OD}$, pertencem à categoria $\mathrm{SN}$ e podem coocorrer com vários tipos de modificadores, como em (11) a (13).

(11) Chovia uma chuva miudinha.

(12) Chovia uma chuva de gotas pesadas 4 .

(13) Chovia uma chuva que não me molhava 5

Em (11) encontramos um objeto cognato composto por $\mathrm{N}$ antecedido de determinante indefinido e seguido de adjetivo $\left(\mathrm{SN}=\left[\mathrm{Det}_{\text {ind }}+\mathrm{N}+\mathrm{Adj}\right]\right.$; o núcleo do $\mathrm{OC}$ de (12) está seguido de $\mathrm{SP}\left(\mathrm{SN}=\left[\operatorname{Det}_{\text {ind }}+\mathrm{N}+\mathrm{SP}\right]\right)$ e o de (13) de uma oração relativa adjetiva restritiva $\left(\mathrm{SN}=\left[\right.\right.$ Det $_{\text {ind }}+\mathrm{N}+$ Oração Relativa $\left.]\right)$. Estas mesmas restrições e condições de ocorrência verificam-se no segundo subtipo de OC verdadeiros (dormir-sono), como os exemplos (14) a (16) ilustram.

(14) Dormia um sono profundo.

(15) Dormia um sono de muitas horas.

(16) Dormia um sono que a deixava tranquila.

nome correspondente, a não ser sommeil); b) por outro lado, seria muito importante saber se existem ou não construções correspondentes com verbos leves, como dar, fazer, ter (no Português do Brasil, existem construções como dar uma dormida, dar uma lida ...).

${ }^{4}$ Exemplo da Web, http://desmondier.blogspot.com/2010/06/chuva.html (27/02/2012).

5 Exemplo da Web, http://foradabolha.blogspot.com/2008_12_01_archive.html (27/02/2012). 
Em síntese, o que parece poder concluir-se é que existem duas condições para a gramaticalidade das construções com verdadeiros cognatos em PE: indefinitude e modificação.

Apresentamos a seguir (quadro 1) uma síntese das propriedades restritivas típicas dos OC verdadeiros em PE:

Quadro 1

Propriedades restritivas típicas dos OC verdadeiros

\begin{tabular}{|l|l|}
\hline \multicolumn{1}{|c|}{ Propriedades } & \multicolumn{1}{c|}{ OC verdadeiros em PE } \\
\hline Definitude & indefinidos \\
\hline Modificação restritiva & presença de adjetivo, SP ou OR \\
\hline Categoria e estrutura do constituinte & SN [D ind+N+Adj/SP/OR] \\
\hline
\end{tabular}

Vejamos mais de perto algumas construções em PE, a fim de refletir sobre os vários tipos de construções cognatas que podem existir nesta língua.

\subsection{OUTROS TIPOS DIFERENTES DE OC}

Nos estudos sintáticos disponíveis sobre o PE tem sido dado o mesmo tratamento aos OC verdadeiros ( $c f$. chover uma chuva ...; dormir um sono ...) e a construções aparentadas ( $c f$. dançar uma dança...), razão pela qual não estão ainda definidas claramente as propriedades que os distinguem. Estas últimas construções são muitas vezes confundidas com as que contêm objetos cognatos (por exemplo, em Duarte e Brito, 2003: 185) porque, por um lado, são pleonásticos (no sentido em que os verbos têm uma variante intransitiva / inergativa, que pode surgir isolada e sem qualquer objeto) e, por outro, porque, tal como os OC verdadeiros, coocorrem com indefinido e adjetivo restritor. Contudo, em relação a verbos como dançar, já não pesam as mesmas restrições sintáticas de definitude e de modificação (ver a propósito os exemplos (5) e (6)) que sobre as construções com OC verdadeiros. Só este comportamento justificaria em PE uma diferença nos objetos cognatos, levando a considerar um segundo tipo - os OC aparentados - distinto dos OC verdadeiros.

Esta situação contrasta com a vasta literatura especializada sobre o Inglês, onde é clara apenas a distinção entre OC e OH (Hale \& Keyser, 2002):

(17) He danced a dance.

(18) He danced $a$ jig. (Hale \& Keyser, 2002: 71)

Também em PE tal distinção é visível, como ilustrado em (19) e (20).

(19) Ele dançou uma dança. (OC aparentado)

(20) Ele dançou um tango. (OH) 
De facto, nos exemplos (18) e (20), temos objetos que referenciam um tipo específico de dança - a jig e um tango - estabelecendo com o verbo uma relação semântica, muito marcada culturalmente em cada comunidade, e não uma relação morfológica como em chover - chuva. Por outro lado, este tipo de objetos parece não reagir da mesma forma que os $\mathrm{OC}$ verdadeiros quanto ao critério da modificação restritiva, podendo surgir sem modificador adjetival ou preposicional, como a gramaticalidade dos exemplos (18) e (20) evidencia, tal como nos OC aparentados e contrariamente ao que se verifica nos $\mathrm{OC}$ verdadeiros (cf. os dados em (5) a (7)). Relativamente à definitude, também não parece ser um critério exigido pelos $\mathrm{OH}(21)$ :

(21) a) Ele dançou o tango alegre ${ }^{6}$.

b) Ele dançou o tango.

Com efeito, a gramaticalidade das construções (21) comprova que o $\mathrm{OH}$ dançar - tango é muito menos restritivo do que as construções com OC verdadeiros, chover uma chuva.../ dormir um sono...

Assim, adotaremos para o PE, além da classe dos OC verdadeiros, a distinção feita por Hale \& Keyser (2002) entre OC e OH, o que, mais uma vez, nos leva a discordar de Real-Puigdollers (2008), quando refere que, nas Línguas Românicas, os OC "are always identical to OH” (Real-Puigdollers, 2008: 159).

Embora esta distinção entre $\mathrm{OC}$ e $\mathrm{OH}$ seja fundamental, pensamos que outras distinções se justificam em PE.

Neste sentido, outros critérios devem ser usados. Um deles é a natureza categorial dos objetos. Até este momento, todos os exemplos em causa comportavam SNs como objetos. No entanto, verbos como morrer, nascer e caminhar, dependendo das línguas em que ocorrem, podem combinar-se com SPREPs ou com SNs (Real-Puigdollers, 2008: 159):

(22) a) He died [of] a slow death. [Inglês]

b) Ele morreu uma morte lenta. [Português do Brasil]

c) Murió de una muerte lenta. [Espanhol]

d) Ele morreu de uma morte lenta. [Português Europeu]

e) Il est mort d'une mort lente. [Francês]

(23) a) They walked [on] a difficult way. [Inglês]

b) Caminharam um caminho dificil. [Português do Brasil]

c) Caminaran por un camino dificil. [Espanhol]

d) Caminharam por um caminho dificil. [Português Europeu]

e) Ils ont marché par un chemin dur. [Francês]

Em Inglês, em (22a) e (23a), temos objetos cognatos SN, sem necessidade de realização de preposição; a aceitarem-se os exemplos (22b) e (23b) como grama-

${ }^{6}$ Estamos aqui a afastar uma leitura em que alegre é um predicado (predicação secundária ou oração pequena). 
ticais, também o Português do Brasil admite SNs cognatos com os verbos morrer e caminhar. Porém, noutras línguas românicas, como o Espanhol, o Português Europeu e o Francês ${ }^{7}$, e com estes verbos, os OC são grupos preposicionais, $(22 \mathrm{c} / \mathrm{d} / \mathrm{e})$ e $(23 \mathrm{c} / \mathrm{d} / \mathrm{e})$; chamá-los-emos provisoriamente objetos cognatos preposicionais (OCP), sendo que, por limites de espaço, deixaremos para futuros trabalhos a sua análise.

A apresentação das propriedades acabada de realizar permite fazer a seguinte proposta de organização dos OC numa língua como o PE, afastando-nos de alguma literatura em que os quatro tipos são designados por OC, como se se tratasse de um conjunto homogéneo, e que não dá conta das diferenças estruturais postas agora em evidência.

(i) OC verdadeiros: (i) o nominal está morfologicamente relacionado com o verbo; são estruturas que exigem indefinido e modificador restritivo, chover-chuva, tossir-tosse...; (ii) o nominal, embora não esteja morfologicamente relacionado com o verbo, mantem uma dependência semântica estrita com ele e não pode ser substituído por um OC morfológico: dormir-sono.

(ii) OC aparentados: o nominal está morfologicamente relacionado com o verbo e, por isso, parece cognato; mas, porque são construções que não têm as mesmas restrições sintáticas, nomeadamente o indefinido e o modificador restritivo, não podem ser consideradas OC verdadeiros: dançar-dança.

(iii) $\mathrm{OH}$ : o nominal exprime um subtipo da entidade denotada pelo nome morfologicamente relacionado com o verbo ou semanticamente dependente dele; não exige indefinitude nem modificação restritiva obrigatórias: dançar-tango.

(iv) OCP: trata-se de um SP que contém um nome morfologicamente relacionado com o verbo, distinguindo-se dos verdadeiros OC pelo facto de serem encabeçados por uma preposição, exigida pelo verbo em PE, embora tal exigência não seja comum a todas as línguas: caminhar por um caminho, morrer de uma morte...

Apresentamos a seguir (quadro 2) uma síntese das propriedades das diferentes classes de OC em PE.

${ }^{7}$ Em Francês, os OCP são muito comuns, afastando-se quer do Espanhol quer do Inglês, em que temos $\mathrm{SN}$ :

(1) a) Rire d'un rire d'enfant. [Francês]

b) Reir la risa de un niño. [Espanhol] (Mendikoetxea, 1999: 1578)

(2) a) Elle a dormi du sommeil du juste. [Francês]

b) She slept the sleep of the just. [Inglês] (Hale \& Keyser, 2002: 71)

(3) a) Il a ri de son dernier rire. [Francês]

b) He laughed his last laugh. [Inglês] (Hale \& Keyser, 2002: 71) 
Propriedades das classes de OC em PE

\begin{tabular}{|l|c|c|c|c|}
\hline & OC verdadeiros & OC aparentados & OH & OCP \\
\hline Morfologia V-N & \pm & + & - & + \\
\hline $\begin{array}{l}\text { Determinação } \\
\text { indefinida }\end{array}$ & + & \pm & \pm & + \\
\hline $\begin{array}{l}\text { Modificador } \\
\text { restritivo }\end{array}$ & + & \pm & \pm & + \\
\hline Preposição & - & - & - & + \\
\hline
\end{tabular}

Na próxima secção do texto começaremos a discutir a análise das construções com OC verdadeiros, com $\mathrm{OC}$ aparentados e com $\mathrm{OH}$.

\section{ANÁLISE LEXICALISTA DAS CONSTRUÇÕES COM OC E $O H$}

É quase impossível analisar os $\mathrm{OC}$ e os $\mathrm{OH}$ sem referir o tratamento que sobre eles tem sido feito por Hale e Keyser.

Hale \& Keyser (1993) propõem que os verbos inergativos, em Inglês (como dance, laugh), sejam considerados subjacentemente "transitivos" ou "transitivos escondidos", sendo formados através de um processo lexical (abstrato, portanto) ("l-syntactic") de incorporação, por um movimento de núcleo, como é ilustrado na derivação de a. para b. em (24).
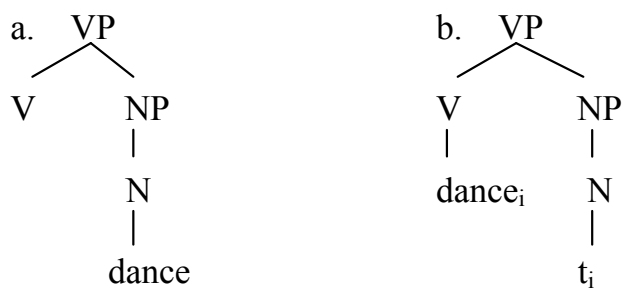

Em Hale \& Keyser (1998) são dadas evidências de várias línguas, inclusive línguas com marcação de caso (por exemplo o Miskitu, crioulo da Nicarágua), que atestam o possível spell out daquela estrutura transitiva alegadamente escondida: "A subset of Miskitu unergatives, generally verbs of noise production ( $c f$. kuhb'cough') are marked by means of an elemento $-b$-, in the same morphological position as the transitivity markers in the alternating set" (Hale \& Keyser, 1998: 115).

No quadro de Hale \& Keyser (2002), a proposta da formação dos verbos inergativos por incorporação é refinada. Todos estes verbos são identificados como verbos denominais e com uma estrutura argumental monádica, projetando apenas um argu- 
mento. O que acontece é que, no léxico, o núcleo (V) não projeta um especificador e o complemento não motiva uma projeção, o que leva a que não seja licenciado um argumento interno. Neste sentido, o argumento sujeito é introduzido na sintaxe (e é externo). Esta estrutura, por princípio, não licenciaria a realização do nome dance na posição de complemento, ou seja, impediria o spell out da estrutura transitiva.

Em parte por esta razão, a operação de incorporação (movimento de um núcleo nominal para uma posição de núcleo verbal vazio), como descrito em (24), é melhorada, de modo a captar a existência de OC em Inglês e passa a designar um processo de movimento por cópia; os autores introduzem então a noção de «conflation», consistindo tal noção no «[...] process of copying the p-signature of the complement into the psignature of the head, where the latter is "defective"» (Hale \& Keyser, 2002: 63). Hale $\&$ Keyser (2002: 93) justificam o licenciamento do complemento escondido com base na hipótese de relação semântica entre $\mathrm{N} \mathrm{e} \mathrm{V}$, como os parêntesis em (25) ilustram.

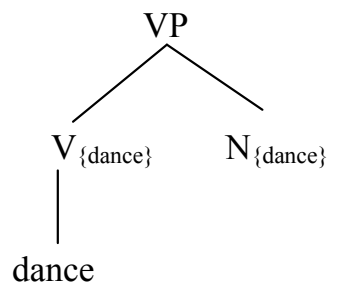

Alguns autores consideram este tratamento problemático, em particular Ramchand (2008: 97), num modelo generativo-construcionista, Haugen (2009: 246), no quadro da MD; Gallego (2012: 98), no quadro da Programa Minimalista, no sentido em que os mesmos verbos que apresentam OC com restrições formam também (e livremente) objetos diretos hipónimos (ver estrutura (26)), os quais negariam a possibilidade de os verbos denominais serem formados na posição de complemento ${ }^{8}$. De facto, tais verbos não poderiam resultar de uma incorporação nominal numa raiz verbal fonologicamente defetiva, uma vez que aquela posição está ocupada pelo verdadeiro complemento - o objeto hipónimo ( a jig) - que não se pode justificar por identidade morfológica (dado que não apresenta a mesma raiz que o verbo anteriormente formado por incorporação nominal/conflation). A única hipótese de salvar a proposta até aqui apresentada por Hale e Keyser é admitir que o $\mathrm{OH}$ possa ser introduzido só na sintaxe e por Inserção Tardia (cf. também Gallego, 2012), operação apenas permitida num quadro não lexicalista.

${ }^{8}$ De acordo com Hale \& Keyser, os objetos cognatos não colocam tal problema, por exemplo "He laughed his last laugh". A teoria do movimento por cópia (Chomsky, 1995) permite explicar ambas as cópias do elemento movido (Hale \& Keyser, 2002: 72; Haugen, 2007: 246), projetando mais que uma cópia em pontos diferentes da estrutura sintática. 
(26)

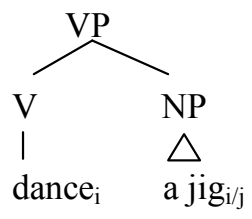

No entanto, o que importa observar é que os verbos com OC verdadeiros não admitem (ou muito dificilmente permitem) a construção com $\mathrm{OH}$; existem, de facto, pelo menos duas construções com OC: as que admitem objeto cognato aparentado e $\mathrm{OH}$ e as que apenas admitem $\mathrm{OC}$ (por nós considerados cognatos verdadedeiros na secção 2). Com efeito, $\mathrm{OC}$ e $\mathrm{OH}$ são distintos no Inglês, e também no PE (e outras Línguas Românicas), porque os verdadeiros verbos com OC, no Inglês, não permitem construções com objetos hipónimos, veja-se a agramaticalidade de (28).

(27) to sleep $+\mathrm{OC}$

She slept the sleep of the just.

(28) $*$ to sleep $+\mathrm{OH}$

* She slept her last napla long winter slumber.

Por outro lado, tais verbos também rejeitam a pronominalização, como mostra a má formação da construção com OC (29), enquanto as construções com $\mathrm{OH}$ a permitem (30) (Hale \& Keyser, 2002: 71).

(29) * to sleep + OC / pronominalização

* John slept the sleep of the just and Bill slept it too.

(30) to dance $+\mathrm{OH} /$ pronominalização

John danced the tango and Bill danced it too.

Tal distinção é notada por Hale e Keyser e poderia até ter repercussão na análise destes autores, aceitando-se, assim, que apenas os verbos com OC verdadeiros, do tipo to sleep, pudessem ser formados por incorporação nominal ou conflation.

No que diz respeito ao $\mathrm{PE}$, o principal constrangimento quanto à aceitação da proposta de Hale \& Keyser é a impossibilidade de explicar pela mesma operação lexical a formação dos verbos que admitem ambas as construções (isto é, verbos com OC aparentados e verbos com $\mathrm{OH}$ ), como dançar uma dança/ um tango, cantar uma cantiga/ um Fado, beber uma bebida/um sumo e comer uma comida/ um cozido à Portuguesa $a^{9}$. Tudo indica, portanto, que quer com OC aparentados quer com $\mathrm{OH}$ estamos

9 Veja-se que Gallego (2008, 2012: 108) denomina as construções (i), com os verbos cantar, beber e comer, de hipónimos alternantes.

(i) a. Cantar una canción/una copla.

b. Beber una bebida refrescante/una Fanta.

c. Comer una comida asturiana/una fabada. 
perante argumentos verdadeiros do verbo, gerados na posição de complemento, o que impede a existência prévia de um nominal na mesma posição.

Neste sentido, apenas os OC verdadeiros em línguas como o Inglês poderiam ser tratados por incorporação / conflation. Pelo contrário, quer os OC aparentados (to dance a dance) quer os $\mathrm{OH}$ (to dance a jig) são selecionados pelos verbos e são seus argumentos diretos (Hale \& Keyser, 2002), não podendo, portanto, ser explicados pela mesma operação. Tal constatação obriga-nos a repensar este quadro e a procurar modelos teóricos capazes de explicar mais cabalmente as várias construções existentes nas Línguas Românicas e no Inglês.

\section{CONTRIBUTOS DA MORFOLOGIA DISTRIBUÍDA PARA A ANÁLISE DAS CONSTRUÇÕES EM ESTUDO}

\subsection{PROPOSTA DE HAUGEN $(2008,2009)$ PARA O TRATAMENTO DOS $O C$ E $O H$}

No caso específico dos OC, Haugen (2009) adota a teoria da MD (Halle \& Marantz, 1993, 1994; Harley \& Noyer, 1999) para explicar que é a estrutura que determina a formação das palavras e grande parte do significado das construções, portanto, um modelo diametralmente oposto ao modelo lexicalista de Hale e Keyser, como foi notado acima. Segundo Haugen (2009), a revisão da noção de conflation de Hale \& Keyser (2002) não é inteiramente satisfatória, em particular porque uma complementação estrita limitada por conflation não exclui a possibilidade de um "resíduo" (por exemplo um adjetivo).

As propriedades mais importantes da MD para as propostas de Haugen (2008, 2009) sobre objetos cognatos são, por um lado, a noção de Inserção Tardia, a ideia de que "syntactic categories are purely abstract, having no phonological content" (Harley \& Noyer, 1999: 3, citado por Haugen, 2008: 248) e, por outro, a não primazia das categorias rotuladas de nomes e verbos (as raízes são subespecificadas sem traços de categoria). Desta forma, a MD posiciona a estrutura sintática hierárquica ao longo do percurso, incluindo projeções funcionais ( $n$ ou $v$ ) que contam com raízes para serem interpretadas.

Haugen assume a Teoria da Cópia de Chomsky (1995), em que os traços são vistos como cópias totais de um elemento movido, sendo coindexados através de uma cadeia de movimentos. Com a Inserção Tardia estas cópias são feixes de traços mais do que material vocabular morfologicamente especificado, não sendo apagados depois de copiados.

A partir destas ideias, a tese central de Haugen (2009: 248) é a de que podemos resolver o problema das construções com $\mathrm{OH}$ admitindo a inserção de raízes nominais não cognatas dentro de cópias altas e baixas depois de a operação de movimento por cópia ser aplicada. O nominal mais baixo será interpretado como hipónimo, sendo qualquer raiz nominal inserida dentro do núcleo da cadeia de movimentos/cópias. 
Segundo a tradicional Teoria da Cópia, a derivação deste tipo de incorporação é simples: a componente sintaxe spell out uma cópia do complemento na posição incorporada (i.é. anexada ao $v$ ) como se aí fosse gerada e deixa traços na posição base do complemento. Haugen considera que "The complex verb then moves higher up the tree for tense, aspect and mood inflection, as per standard incorporation" (Haugen, 1999: 249).

O autor aceita, por consequência, a possibilidade de spell out as duas cópias em simultâneo: a cópia baixa e a cópia alta anexada ao $v$. Veja-se que Haugen entende a operação de incorporação não só como o movimento do nominal para a posição verbal (como em Hale \& Keyser, 1993), mas também, no seguimento da Teoria da Cópia (Chomsky, 1995), em que a operação envolve cópia ('copying') em vez de movimento em sentido estrito. Este entendimento é importante para Haugen na análise das construções com OH: (i) o feixe de traços da raiz é inserido na componente sintática do complemento de $v$ (por Inserção Tardia) e incorporado; (ii) projetam-se, em simultâneo, este feixe, já copiado para $v$, e mais uma raiz, capaz de realizar traços especificados.

Permitindo a inserção de material lexical não cognato na posição de complemento de $v$, numa posição de cópia baixa, Haugen resolve de forma relativamente elegante a problemática dos $\mathrm{OH}$. Além disso, na sua perspetiva, poderíamos aceitar que condições pragmáticas específicas das línguas (máxima da quantidade de Grice, por exemplo) justificam a inserção de determinadas raízes e o seu spell-out em determinadas posições da cadeia de movimentos (Haugen, 2009: 253 e ss.). No entanto, o autor não apresenta qualquer estrutura sintática para o Inglês ${ }^{10}$, nem com $\mathrm{OC}$ nem com $\mathrm{OH}$; é também omisso quanto às nominalizações deverbais (Ele dançou magnificamente o tango vs. A dança do tango foi magnífica.), além de não distinguir as construções com OC verdadeiros das construções com OC aparentados.

Como já foi mencionado anteriormente, o PE e as Línguas Românicas em geral levantam novas questões no campo do estudo dos verbos com OC e com OH. Justifica-se, portanto, a exploração de uma análise para algumas das construções tratadas neste texto.

\section{A NOSSA PROPOSTA (PROVISÓRIA) DE ANÁLISE DOS OC VERDADEIROS E APARENTADOS E DOS OH EM PE}

Tendo por base propostas da MD, nomeadamente a análise de Haugen (2009), propomo-nos analisar a estrutura de algumas construções com OC verdadeiros, OC aparentados e $\mathrm{OH}$.

${ }^{10}$ As estruturas que Haugen (2009) apresenta são para o Hopi (Uto-Aztecan), língua aglutinante, com uma matriz sintática muito diferente da do Inglês. 
Não há dúvida que a aceitação dos $\mathrm{OC}$ verdadeiros (chover uma chuva ..., sonhar um sonho..., dormir um sono...) é constrangida, tal como enunciado no ponto 1., pela presença de um determinante indefinido e um modificador restritivo, condições obrigatórias para a gramaticalidade destas construções, sendo tais condições opcionais quer para as construções com $\mathrm{OC}$ aparentados (dançar uma dança) quer com $\mathrm{OH}$ (dançar um tango).

Admitindo, então, que a sintaxe é a única componente gerativa do sistema, as raízes ( $l$-morfema) abstratas e acategoriais (desprovidas de qualquer forma fonológica) são inseridas no nó terminal, associando-se, por merge, a um morfema funcional (os $f$-morfemas, podendo ser $n, v, a$ ), como se ilustra em (31).

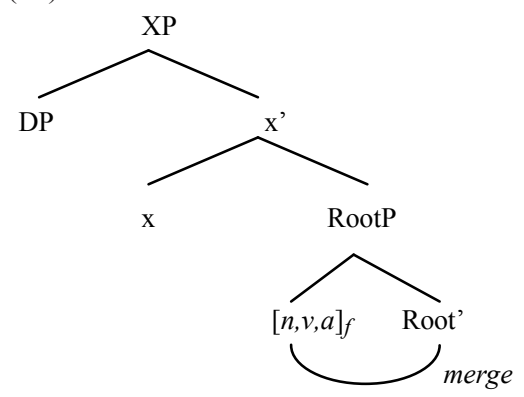

Esta operação permite a realização fonológica da raiz e atribui-lhe uma especificação, criando um Item de Vocabulário. No caso particular das nossas construções, as raízes serão associadas a um $f$-morfema verbalizador $(\ldots v)$.

Vejamos, em primeiro lugar, o caso das construções com OC verdadeiros, como na frase (1a), aqui repetida em (32a).

(32) a) Chovia uma chuva miudinha. (OC verdadeiro)

b) Chovia. (OC escondido)

A análise de (32a) de acordo com os pontos anteriores é esboçada em (33).

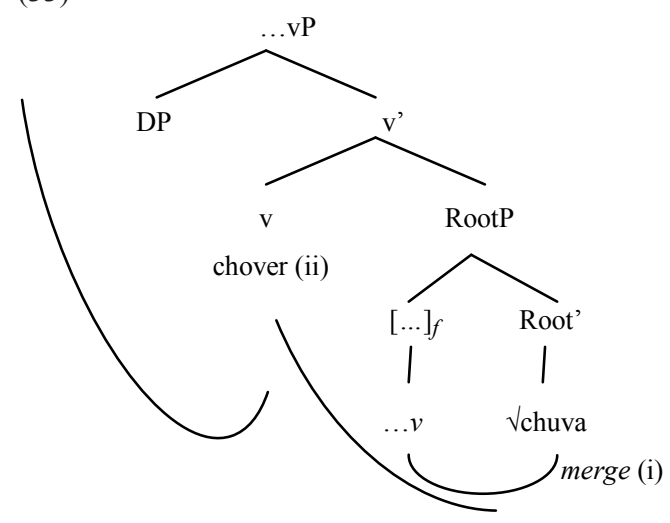


$\mathrm{O}$ item de vocabulário que resulta do merge da raiz com o $f$-morfema verbalizador (etapa (i)) é, pelo processo de movimento por cópia, copiado para $v$ (etapa (ii)), deixando traços fonológicos na posição da raiz (cópia baixa), que podem ou não ser projetados no módulo Enciclopédia ${ }^{11}$, sendo desta opção que resultam a construção (32a) ou a construção (32b). Na construção (32b) entende-se OC escondido na linha de Hale e Keyser, como descrito em 2.

Neste momento, e como a construção apresentada em (32a) realiza o OC com o núcleo chuva, a mesma raiz, num só spell out, efetiva as duas cópias: a cópia alta (núcleo de [v, v']), que ascende posteriormente a fim de verificar os traços de Voice, Asp e Tempo, específicos das formas verbais flexionadas; e a cópia baixa (núcleo de [Root', RootP]), que se move para a posição de especificador de $\mathrm{vP}$ a fim de verificar os traços de caso acusativo, como se ilustra resumidamente em (34).

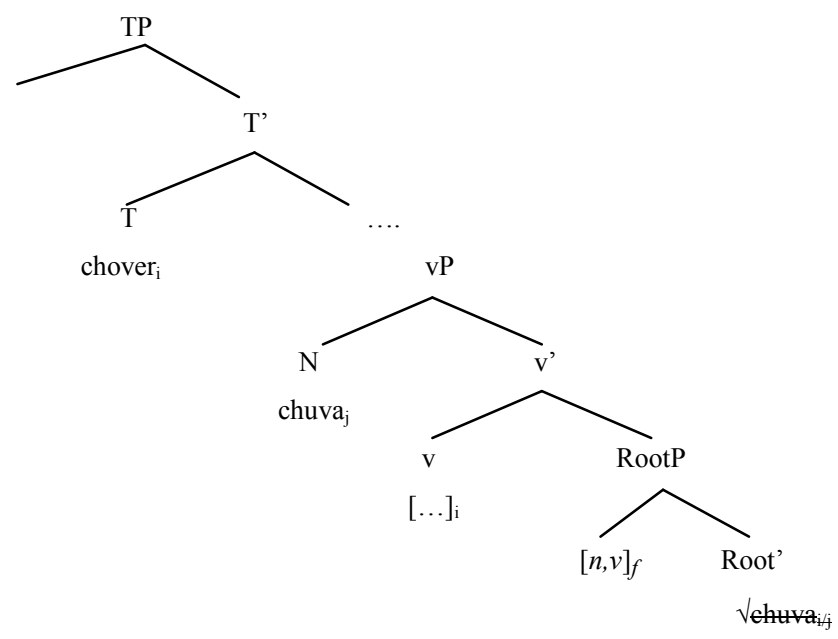

No entanto, para a estrutura em (34) ser gramatical torna-se necessário que o especificador de vP seja um DP, integrando o determinante indefinido e o modificador do nome cognato, duas condições exigidas para o licenciamento semântico-pragmático das construções em PE, como repetidamente foi afirmado acima.

Assim, em (35) esboçamos a estrutura em que na posição da cópia baixa é projetado um $\mathrm{DP}^{12}$ e não apenas um $\mathrm{N}$.

${ }^{11} \mathrm{O}$ módulo Enciclopédia é uma das três componentes que integram a arquitetura de gramática em MD, contendo entradas que relacionam itens de vocabulário a significados, podendo albergar informações extralinguísticas, relacionadas com a interpretação semântica dos elementos já gramaticalmente formados.

12 Ramchand (2008), num modelo generativo-construcionista, defende que a única forma de licenciar este DP é unificá-lo com o conteúdo léxico-enciclopédico do item verbal, sendo que no 
(35)

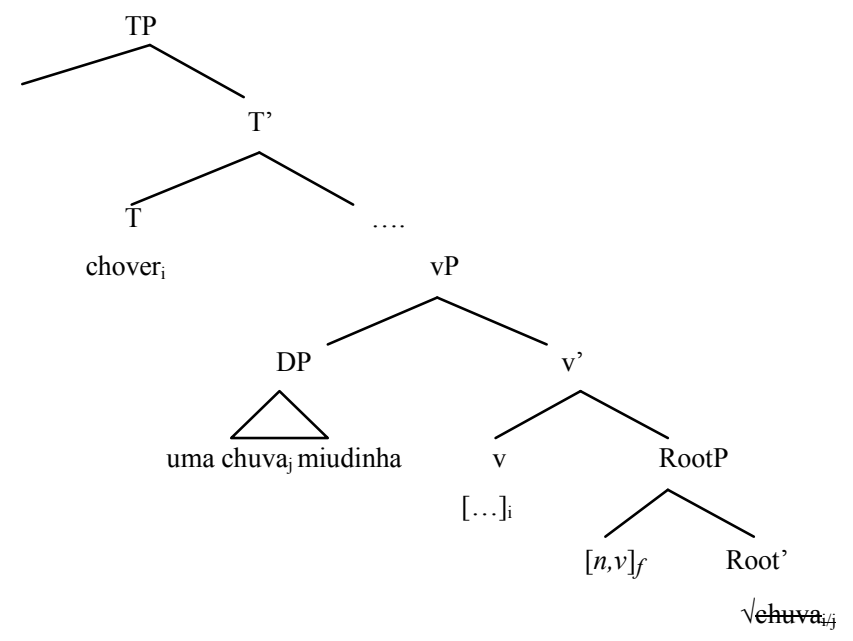

Se a construção não realizar o $\mathrm{OC}$, como em (32b), apenas será projetada uma cópia, a cópia alta, que contém a forma fonológica de chover, embora os traços da cópia baixa não sejam apagados, o que faz, segundo Haugen, com que discursivamente possam ser recuperados. Na nossa proposta fica por explicar a razão para a não homonímia perfeita entre todos os pares V-N nas construções com OC verdadeiros; isto é, o porquê de uma língua, como o $\mathrm{PE}$, não disponibilizar nestes contextos certas raízes, como a agramaticalidade em (36) mostra.

(36) *dormir uma dormida...

Uma possível explicação para a agramaticalidade de (36) é o facto de o PE fazer largo uso de verbos leves (ter, dar e fazer) como paráfrase para estas construções com OC, neste caso, fazer uma dormida. De qualquer modo, como já referimos na nota de rodapé número 3., o PB é mais aberto a construções com objetos cognatos do tipo de (36).

Vejamos agora os exemplos das construções com OC aparentados (37) e $\mathrm{OH}$ (38).

(37) Ele dançou uma dança triste. (OC aparentado)

(38) Ele dançou um tango. (OH)

As duas primeiras etapas são as mesmas que as dos OC verdadeiros: a raiz abstrata é inserida em Root', portanto, na cauda da estrutura sintática; por merge associa-se

caso dos OC verdadeiros será pela especificação do nominal (por exemplo, sleep e laugh, She slept the sleep of the just, He laughed his last laugh) em si, através de modificação. Pelo contrário, o nominal do tipo a jig em He danced a jig, apresenta uma unificação com a raiz verbal por existir como hipónimo lexicalizado pronto, sem obrigatoriedade de modificador restritivo (Ramchand, 2008: 98). 
ao $f$-morfema verbalizador e por move e cópia desloca-se para o núcleo de [v, v'], deixando um feixe de traços na posição de origem (cópia baixa). No entanto, há uma diferença importante a registar nas etapas seguintes: apenas a cópia alta é projetada e é visível fonologicamente; na posição da cópia baixa é inserido, por Inserção Tardia, novo material lexical, que pode ser cognato ou não cognato (etapa iii). No caso dos OC aparentados (dançar uma dança triste), a segunda raiz inserida é morfologicamente idêntica à primeira (já movida para $[\mathrm{v}, \mathrm{v}$ ']), havendo total identidade entre o feixe de traços das duas raízes. No caso dos $\mathrm{OH}$, o material inserido é não cognato, sendo que os traços desta raiz e os da cópia baixa são parcialmente coincidentes, estabelecendo-se apenas uma relação de hipo/hiperonímia entre a raiz que deu origem ao verbo e a do $\mathrm{OH}$. Veja-se a estrutura em (39).

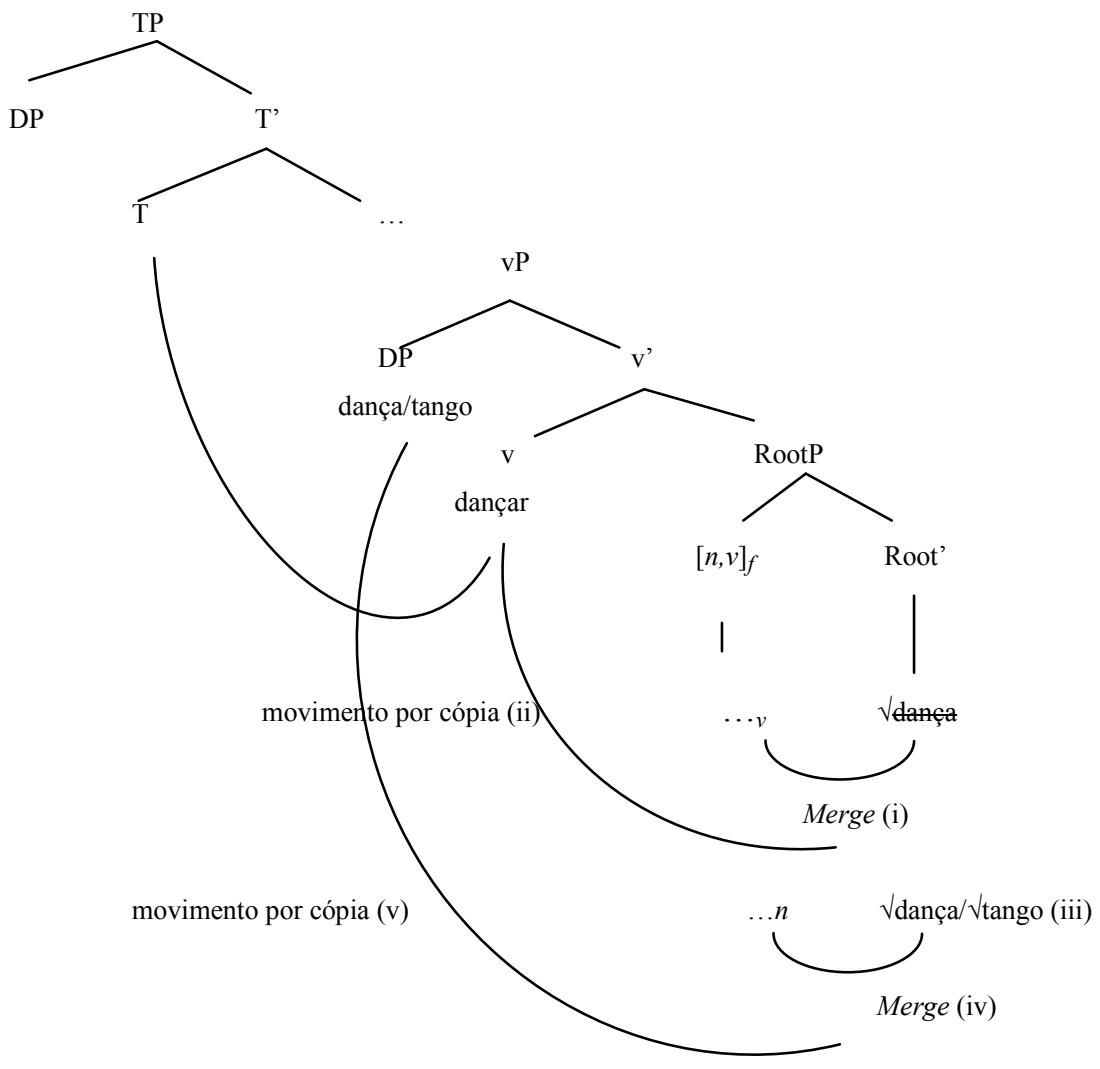

É importante reforçar que as raízes inseridas quer numa quer noutra construção (OC aparentados e $\mathrm{OH}$ ) são projetadas em momentos diferentes da formação da estrutura hierárquica; há, portanto, dois spell out em cada construção, sendo este o ponto que nos permite diferenciar a cognação aparente da cognação com $\mathrm{OC}$ verdadeiros 
(em que as duas cópias resultam do mesmo spell out e têm origem na mesma raiz). Não estando estas construções sujeitas ao mesmo tipo de licenciamento sintático-semântico que os $\mathrm{OC}$ verdadeiros, uma vez que não há obrigatoriedade de indefinitude e modificação nominal, parece-nos, no entanto, que algo tem de justificar o aparecimento de um determinante (neste caso definido ou indefinido) e o adjetivo ou outro modificador (um tango/o tango/o tango triste). Por todas estas razões, tudo leva a crer que, no caso das construções analisadas em (39), estamos perante argumentos internos dos verbos, verdadeiros complementos verbais, sendo que a relação morfológica entre $\mathrm{V}$ e $\mathrm{N}$ pode resultar de uma coincidência.

\section{CONCLUSÕES}

Uma das primeiras conclusões que decorre deste estudo é a existência em PE de, pelo menos, quatro construções distintas: (i) OC verdadeiros (chover-chuva, tossir-tosse, dormir-sono...); (ii) OC aparentados (dançar - dança); (iii) OH (dançar-tango); (iv) OCP (caminhar por um caminho, morrer de uma morte...).

A existência de algumas expressões lexicalizadas, quase idiomáticas, em certas Línguas Românicas, não parece justificar um tratamento tão diversificado no interior destas línguas e entre estas e o Inglês, como foi notado por Real-Puigdollers.

Outra das ideias apenas esboçada neste estudo é a importância do confronto entre as construções com OC e as construções com verbos leves; parece, por exemplo, que a impossibilidade de $\mathrm{OC}$ com certos verbos inergativos (como *dormir uma dormida) poderá ser explicada pela produtividade das paráfrases com verbos leves (como fazer uma dormida).

Apesar de o Inglês ter casos de homonímia perfeita entre palavras de classes diferentes (to sleep/ a sleep; to laugh/ a laugh...), o que justificou um tratamento deste fenómeno com base no mecanismo de incorporação nominal, a distinção entre OC e OH exige um tratamento mais completo e diverso do que Hale e Keyser propuseram. Neste sentido, o tratamento lexicalista destes autores, embora tenha lançado as bases para o estudo deste fenómeno, não permite resolver cabalmente os problemas levantados por outras línguas, nomeadamente o PE, razão pela qual experimentámos outros tratamentos. Algumas ideias da MD, em particular de Haugen (2009), articuladas com algumas noções do Programa Minimalista, permitiram-nos fazer uma análise de algumas construções, nomeadamente com OC verdadeiros, OC aparentados e $\mathrm{OH}$, baseada na ideia de movimento por cópia e de inserção tardia na posição da cópia baixa.

No entanto, várias questões ficam por responder, uma vez que nenhum dos modelos teóricos convocados permite analisar cabalmente as construções com OC. A este problema procuraremos voltar em trabalhos futuros. 


\section{AGRADECIMENTOS}

Agradecemos o precioso contributo e a orientação de Ana Maria Brito neste trabalho, sem os quais não poderíamos ter aqui chegado. Agradecemos igualmente aos organizadores e à audiência do colóquio L'interface de la syntaxe et de la sémantique lexicale. Synchronie \& diachronie, realizado em Poznan, 9 março de 2012, onde foi apresentada a comunicação Quelques apports de la Morphologie Distribuée pour l'analyse syntaxique des objets cognats en PE, que esteve na base deste estudo.

\section{BIBLIOGRAFIA}

Choupina, Celda (2011): «Tipos de objetos cognatos e de objetos hipónimos em PE», comunicação apresentada ao $2^{\circ}$ Encontro de Pós-Graduação em Linguística. Coimbra: CELGA, 9-10 dezembro 2011.

Choupina, Celda (2012a): «Quelques apports de la Morphologie Distribuée pour l'analyse syntaxique des objets cognats en PE», sessão plenária apresentada ao colóquio L'interface de la syntaxe et de la sémantique lexicale. Synchronie \& diachronie. Universidade Adam Mickiewicz, Poznań, 9 março 2012.

Choupina, Celda (2012b): «Os objetos cognatos em Línguas Românicas e no Inglês: aspetos sintáticos e semânticos», comunicação apresentada ao VII ${ }^{e}$ Colloque International «Linguistique contrastive germano-romane et intraromane». Universidade de Innsbruck, 5-8 setembro 2012.

Сномsкy, Noam (1995): The Minimalist Program. Cambridge, Mass.: MIT Press.

Duarte, Inês; Brito, Ana M. (2003): «Predicação e classes de predicadores verbais». In: Maria H.M. Mateus, Ana M. Brito, Inês Duarte, Isabel H. Faria et alii [eds.]. Gramática da Língua Portuguesa. Lisboa: Caminho, 179-203.

Gallego, Ángel J. (2008): Cognate Objects and (Clitic) Doubling, comunicação apresentada ao NORMS, Workshop on Argument Structure. Lund University, 4-6 fevereiro 2008.

Gallego, Ángel J. (2012): «A note on cognate objects: cognation as doubling», In: Kristine Bentzen, Antonio FÁbregas [eds.]. Nordlyd 39.1, 2, special issue on 'The Grammar of Objects'. Tromsø: University of Tromsø. 95-112. URL: <http://www.ub.uit.no/baser/nordlyd/>. Último acesso 11/05/2012.

Grevisse, Maurice; Goosse, André (1993): Le bon usage. Bruxelles : De Boeck-Duculot.

Hale, Kenneth; Keyser, Samuel J. (1993): «On Argument Structure and the Lexical Expression of Syntactic Relations». In: Kenneth Hale, Samuel J. Keyser [eds.]. The View From Building 20: Essays in Linguistics in honour of Sylvain Bromberger. Cambridge. Mass.: MIT Press. 53-109.

Hale, Kenneth; Keyser, Samuel J. (1998): «The basic elements of argument structure». In: Heidi Harley [ed.]. MIT working papers in linguistics 32: Papers from the Upenn / MIT roundtable on argument structure. Cambridge, Mass.: MIT Press, 73-118. URL: <http://web.mit. edu/ linguistics/events/tributes/hale/papers/ch.1>. Último acesso 20/09/2012.

Hale, Kenneth; Keyser, Samuel J. (2002): Prolegomenon to a theory of argument structure. Cambridge, Mass.: MIT Press.

Halle, Morris; Marantz, Alec (1993): «Distributed morphology and the pieces of inflection». In: Kenneth Hale, Samuel J. Keyser [eds.]. The View from Building 20: Essays in Linguistics in honour of Sylvain Bromberger. Cambridge, Mass.: MIT Press, 111-176. 
Harley, Heidi; Noyer, Rolf (1999): «State-of-the-Article: Distributed Morphology». Glot 4.4. 3-9. Haugen, Jason D. (2009): «Hyponymous objects and Late Insertion». Lingua 119 (2): 242-262.

Höche, Silke (2009): Cognate Object Constructions in English. A Cognitive-Linguistic Account. Tübingen: Gunter Narr Verlag.

Hong, Zhou (1999): «Cognate objects in Chinese». Toronto Working Papers in Linguistics, 263-284. URL: <http://twpl.library.utoronto.ca/index.php/twpl/article/view/6265>. Último acesso em 20/02/2012.

Horita, Yuko (1996): «English Cognate Object Constructions and Their Transitivity». English Linguistics 13: 221-247.

Jones, Michael A. (1988): «Cognate objects and the case filter». Journal of Linguístics 24 (1): 89-110.

Kitahara, Ken-ichi (2006): «On the Form and Meaning of Cognate Object Constructions in English: A Construction Grammar Approach». Tsukuba English Studies 25: 125-126.

Kitahara, Ken-ichi (2007): «On the Predicative Cognate Object construction and the Adjunct Resultative Construction: A Construction Grammar Approach to language Universals». Tsukuba English Studies 26: 67-90. URL: <http://www.tulips.tsukuba.ac.jp/limedio/dlam/M92/ M921496/6.pdf>. Último acesso em 27/05/2012.

LEUNG, Renata T.F. (2007): Um estudo sobre os objetos cognatos e os adjetivos adverbiais no português do Brasil. Tese de doutoramento apresentada à Faculdade de Filosofia, Letras e Ciências Humanas da Universidade de São Paulo, São Paulo. URL: < http://www.fflch.usp.br/dl/pos/ teses/LEUNGrenata.pdf>. Último acesso em 20/03/2012.

Leung, Renata T.F.; Scher, Ana P. (2006): «Os Objetos Cognatos e os Modificaores Adverbiais». Estudos Lingüisticos XXXV: 1668-1676.

MASSAM, Diane (1990): «Cognate objects as thematic objects». Canadian Journal of Linguistics 35 (2): 161-190.

Matsumoto, Masumi (1996) «The Syntax and Semantics of the Cognate Object Construction», English Linguistics 13: 199-220.

MendikoetXeA, Amaya (1999) «La inacusatividad en la tipología verbal del español». In: Ignacio Bosque, Violeta Demonte [eds.]. Gramática descriptiva de la lengua española. Madrid: Espasa Calpe, 1575-1629.

Mirto, Ignazio M. (2007): «Dream a little dream of me: Cognate Predicates in English». In: 26 conference on Lexis and Grammar, Bonifacio, 2-6 October 2007. URL: $<$ http://infolingu.univ-mlv. fr/Colloques/Bonifacio/proceedings/mirto.pdf $>$. Último acesso em 20/04/2012.

Pereltsvaig, Asya (1999a): «Two Classes of Cognate Objects». In: Kimary Shahin, Susan Blake, Eun-Sook KIm [eds.]. The Proceedings of the West Coast Conference on Formal Linguistics XVII. Stanford: CSLI Publications, 537-551.

Pereltsvaig, Asya (1999b): «Cognate Objects in Russian: is the notion "cognate" relevant for Syntax?». Canadian Journal of Linguistics / Revue canadienne de linguistique 44 (3): 267-291.

Pereltsvaig, Asya (2002): «Cognate objects in Modern and Biblical Hebrew». In: Jamal Ouhalla, Ur Shlonsky [eds.]. Themes and Issues in Arabic Hebrew. Dodrecht: Kluwer Academic Publishers. 107-136.

Рнам, Hoa (1998): «Cognate objects in Vietnamese transitive verbs». Toronto Working Papers in Linguistics 17: 227-246.

Pustejovsky, James (1991): «The Generative Lexicon». Computational Linguistics 17 (4): 409-441.

Ramchand, Gillian C. (2008): Verb Meaning and the Lexicon: A first phase syntax. Cambridge: Cambridge University Press. 
Real-Puigdollers, Cristina (2008): «The Nature of Cognate Objects. A Syntactic Approach». In: Proceedings ConSOLE XVI. 157-178. URL: <http://www.sole.leidenuniv.nl>. Último acesso em 27/05/2011.

SAILER, Manfred (2010): «The Family of English Cognate Object Constructions». In: Stefan MüLleR [ed.]. Proceedings of the HPSG 10 Conference. Paris: CSLI - Université Paris Diderot (Paris 7). 191-211. URL: <http://csli--publications.stanford.edu>. Último acesso em 27/05/2012.

SiLva, Marcelo Lopes da (2010): As construções com objeto cognato em Português - análise e esboço de modelagem sociocognitiva. URL: <http://marcelolopesdasilva.com.br/index.php/textosdoautor/doc_details/12-2010b-as-construcoes-com-objeto-cognato-em-portugues-analisee-esboco-de-modelagem-sociocognitiva.html>. Último acesso em 27/05/2012. 